\title{
WestVirginiaUniversity
}

THE RESEARCH REPOSITORY @ WVU

Graduate Theses, Dissertations, and Problem Reports

2012

\section{Evaluation of the Use of Raman Spectroscopic Techniques in Ink Analyses}

\author{
Patricia T. Elswick \\ West Virginia University
}

Follow this and additional works at: https://researchrepository.wvu.edu/etd

\section{Recommended Citation}

Elswick, Patricia T., "Evaluation of the Use of Raman Spectroscopic Techniques in Ink Analyses" (2012). Graduate Theses, Dissertations, and Problem Reports. 555.

https://researchrepository.wvu.edu/etd/555

This Thesis is protected by copyright and/or related rights. It has been brought to you by the The Research Repository @ WVU with permission from the rights-holder(s). You are free to use this Thesis in any way that is permitted by the copyright and related rights legislation that applies to your use. For other uses you must obtain permission from the rights-holder(s) directly, unless additional rights are indicated by a Creative Commons license in the record and/ or on the work itself. This Thesis has been accepted for inclusion in WVU Graduate Theses, Dissertations, and Problem Reports collection by an authorized administrator of The Research Repository @ WVU. For more information, please contact researchrepository@mail.wvu.edu. 


\title{
Evaluation of the Use of Raman Spectroscopic Techniques in Ink Analyses
}

\author{
Patricia T. Elswick \\ Thesis submitted to the \\ Eberly College of Arts and Sciences \\ at West Virginia University \\ in partial fulfillment of the requirements \\ for the degree of \\ Master of Science \\ in \\ Forensic Science \\ Keith Morris, Ph.D., Chair \\ Patrick Buzzini, Ph.D. \\ Jonathan Boyd, Ph.D.
}

Forensic and Investigative Science Program

Morgantown, West Virginia

2012

Keywords: Raman spectroscopy, surface-enhanced Raman spectroscopy, questioned documents, ink analysis 


\author{
ABSTRACT \\ Evaluation of the Use of Raman Spectroscopic Techniques in Ink Analyses \\ Patricia T. Elswick
}

The inelastic scattering effects seen in Normal Raman (NR) spectroscopy were first observed in 1928 by Raman and Smekal. One problem encountered with Raman spectroscopy was the Raman scattering being masked by the intense fluorescence produced when the sample was exposed to the laser. One discovery in 1974 by Fleischmann et al. helped to maximize the Raman signal and came to be known as surface-enhanced Raman spectroscopy (SERS). In this research, spectral libraries of dyes used in pens and Raman spectra produced from the analysis of inks were evaluated in order to determine the extent to which inks can be discriminated using Raman spectra. The acid dyes were analyzed at $532 \mathrm{~nm}$ using NR and SERS and at $785 \mathrm{~nm}$ using NR. The results of the acid dye analyses indicated that there was not a single method that could generate usable spectra for all the dyes. NR at $532 \mathrm{~nm}$ produced the most usable spectra. The inks were analyzed both in situ and by extraction with methanol. They were analyzed at $532 \mathrm{~nm}$ using NR and SERS. The in situ analyses only produced usable results for 7 of the inks analyzed. The results of the ink analyses showed the potential for SERS to produce enhanced spectra over NR. Extraction SERS yielded usable spectra for 28 of the 31 inks analyzed, compared to 7 inks and 2 inks for in situ NR and extraction NR, respectively. The extent of the SERS enhancement varied between samples, and some of the spectra generated could not be differentiated. 


\section{TABLE OF CONTENTS}

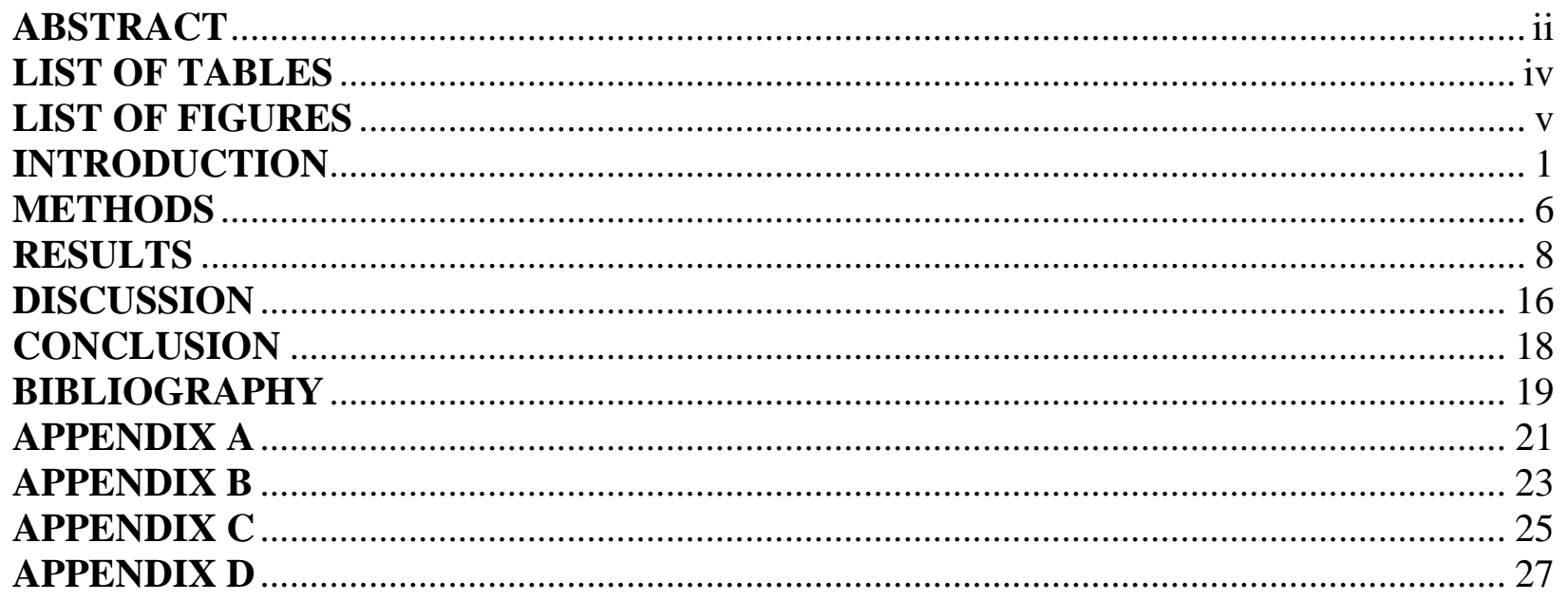




\section{LIST OF TABLES}

Table 1 Counts of usable spectra for each acid dye color group under the three analysis scenarios Table 2

Results of each analysis scenario for each pen brand 


\section{LIST OF FIGURES}

Figure 1 Energy states of molecules in Rayleigh scattering, Stokes shift and anti-Stokes shift Figure 2

Figure 3

Raman spectra of reference dye C.I. Acid Blue 113 and C.I. Acid Black 24

Figure 4 Three Acid Blue dyes analyzed at $532 \mathrm{~nm}$ using NR and their corresponding structures

Figure 5

Figure 6

Figure 7

Figure 8

Figure 9

Figure 10

Figure 11

Figure 12 Acid Yellow 19 spectra at $532 \mathrm{~nm}$ using NR and SERS Test 18 in situ NR Example of increased fluorescence between in situ NR and SERS Spectra showing the difference between NR and SERS extraction Four inks showing similar spectra analyzed using SERS extraction Spectra of Test 19 analyzed in situ NR and SERS and extraction SERS Spectra for Test 18 using in situ NR and SERS and extraction SERS Chemical structures of three acid dyes and their associated spectra 


\section{INTRODUCTION}

Raman spectroscopy was first observed by Raman and Smekal in 1928 (1), and it is often considered the complement of Fourier Transform Infrared (FTIR) spectroscopy. Both techniques irradiate the sample and provide a spectrum indicative of the chemical bonds that are present based on the vibrational modes of the bonds. However, the two techniques differ greatly in how the spectra are obtained. FTIR spectroscopy depends on a permanent change in the dipole moment because of the absorption of light. Raman spectroscopy involves polarization to produce scattering of the light (2).

When photons interact with the molecule they can be scattered in two ways: elastically or inelastically. Elastic scattering, also known as Rayleigh scattering, is when the photon interacts with the sample and there is no energy exchange. With inelastic scattering, or Raman scattering, the photon either loses energy or gains energy depending on the vibrational state of the molecule. A molecule at the ground vibrational level will take energy from the photon producing a Stokes shift. However, if a molecule is already in an excited vibrational state, energy can be transferred to the photon; this is known as anti-Stokes shift $(1,2)$. Figure 1 diagrams the energy states of the molecule in each type of scattering. $\mathrm{E}_{0}$ represents the ground vibrational state, and $\mathrm{E}_{1}$ represents the excited vibrational state. The dashed lines denote the virtual state of the molecule. Raman spectra show the change in the amount of energy detected in the light after interacting with the sample.

Despite its many advantages, Raman spectroscopy had one major limitation. Raman spectra could not be obtained from a number of materials because of the intense fluorescence observed in the visible region. Fluorescence occurs as a result of an electronic transition when a photon is absorbed by a molecule. The absorbed energy is then emitted as light of a longer 
wavelength. The Raman spectra are usually obtained at the lower-energy side to show Stokes shift, but this is where fluorescence has the greatest interference. The fluorescent signal will be more intense than the Raman signal, in effect masking any Raman signal detected. One technique that is utilized to overcome the fluorescence is to record in the anti-Stokes region by selecting the laser wavelength. Using near infrared lasers decreases the amount of energy the molecule is exposed to and does not provide enough energy to excite the molecule to fluorescence. Fleischmann et al. discovered another solution to the fluorescence problem in 1974 when they observed strong Raman scattering from pyridine adsorbed onto a roughened silver electrode surface from aqueous solution (3). This discovery came to be known as surfacedenhanced Raman spectroscopy (SERS).

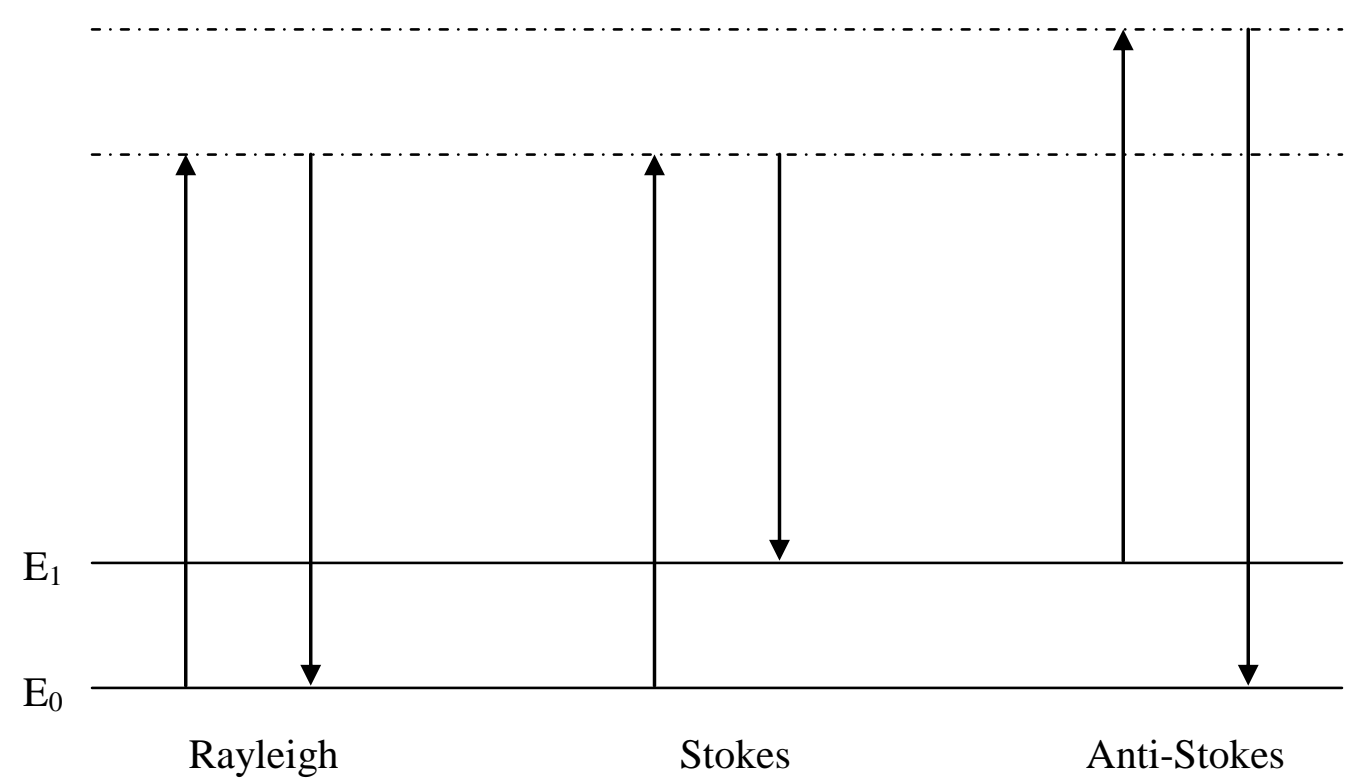

Figure 1: Energy states of molecules in Rayleigh scattering, Stokes shift and anti-Stokes shift

SERS was first encountered in 1974 by Fleischmann $e t$ al. in their work to attempt to develop a probe that could be used to study electrochemical processes in situ (3). The mechanism 
by which SERS works is still not completely understood, but electromagnetic and chemical enhancements are two proposed methods for how SERS increases the Raman scattering (4). Research done by Lombardi and Birke (5) presents a unified expression showing the two methods working together to produce the total SERS effects.

In the electromagnetic theory it is believed that the interaction of surface plasmons with the electromagnetic field of the light used during analysis causes amplification of the incident laser and the scattered Raman field. Surface plasmons are only excited by light if the surface is rough or curved. The application of the silver colloid in SERS analysis produces the necessary surface roughness for surface plasmon excitation and, in turn, enhancement of the Raman signal.

The chemical enhancement theory was suggested when molecules having nearly identical polarizabilities exhibited extreme differences in their SERS intensities. This difference was explained by charge-transfer (6) from molecule to metal or vice versa. The new electronic state that is formed acts as a resonant intermediate state in Raman scattering, increasing the sensitivity by two to four orders of magnitude (7).

The discovery of SERS introduced the possibility of the analysis of samples that once had a fluorescence that masked the Raman spectra. In forensic science, this includes ink samples encountered in the field of questioned documents.

According to the American Society for Testing and Materials, forensic document examiners make scientific examinations, comparisons and analyses of documents in order to (8):

1) Establish genuineness or non-genuineness, or to expose forgery, or to reveal alterations, additions or deletions,

2) Identify or eliminate persons as the source of handwriting,

3) Identify or eliminate the source of typewriting or other impressions, marks or relevant evidence and

4) Write reports or give testimony, when needed to aid the users of the examiner's services in understanding the examiner's findings. 
As part of the duties involved in performing questioned document analyses an examiner may be required to analyze inks. The analysis of inks can indicate the presence of alterations, additions or deletions in a document and can be used to include or exclude a writing instrument as a possible ink source.

Inks are generally composed of vehicles, colorants and additives. The vehicle is the solvent in which the other components are suspended. The colorants consist of pigments, dyes or both. Additives provide the qualities desired by the manufacturer for the specific use of the ink. They can help to control the flow of ink, increase the thickness of the ink or alter the appearance and ink characteristics in other ways. The inks encountered in questioned documents usually originate from printers and pens. The focus of this study will be the ink found in pens.

There are four main classes of pens: ballpoint, felt tip, roller ball and gel. The ballpoint pen is constructed with a small steel ball encased in a housing which allows the ball to roll freely. Ink inside the reservoir of the pen adheres to the ball, and the ink is transferred from the ball to the writing surface as it rolls. The felt tip pen introduced water-soluble inks. The ink is stored in the pen reservoir and flows into the porous tip and on to the writing surface due to capillary action. The roller ball pen combines the structure of the ballpoint pen and the watersoluble ink of the felt tip pen. Gel pens are the newest class of pens developed in Japan. The use of pigments in gel pens differentiates them from most water-based inks that use dyes.

Ink can be analyzed using a number of methods including thin layer chromatography, UV/vis microspectrophotometry, mass spectrometry and Raman spectroscopy. Thin layer chromatography crudely separates the components of the ink allowing for preliminary comparisons. UV/vis microspectrophotometry utilizes the fact that inks of similar color can sometimes exhibit different luminescent properties at different wavelengths due to their chemical 
components. This allows an examiner to visualize alterations on questioned documents. Mass spectrometry coupled with various techniques (9-12) has been used to characterize inks as well as study the degradation of the chemical components for age determination. Raman spectroscopy is also used to determine the chemical composition of the inks.

Studies using Raman spectroscopy on inks have yielded promising results. And the introduction of SERS improved the capabilities of the technique. A 2002 study on discriminating between inks (13) looked at 16 blue ballpoint pen inks which were arranged in 120 ballpoint pen pairs. Using normal Raman spectroscopy, 106 pairs were able to be differentiated. A similar study determined the discriminating power of the Raman technique to be 0.68 for thirty-six blue gel pen inks where the discriminating power was calculated by dividing the number of discriminated pairs by the total number of possible pairs (14). Geiman et al. conducted research (15) indicating that SERS analysis consistently provided increased signal strength and quenched fluorescence when compared to normal Raman spectroscopy in the analysis of pen ink.

To date, the research conducted on Raman spectroscopy has involved limited sample sizes $(4,12-15)$ and has typically used extraction methods for analysis. In forensic science, a non-destructive method would be preferred in order to preserve the integrity of the evidence. While SERS has been shown to have significant advantages over normal Raman spectroscopy in the analysis of inks, a study comparing in situ and extraction SERS analysis had not been carried out.

The first goal of this study was to build a spectral library of seventy-five acid dyes. The normal Raman spectra obtained for the acid dyes were evaluated for inter- and intra- spectral variations. There have been instances (Figure 2) in which normal Raman spectroscopy was unable to differentiate between two dyes. 
The second aim of the study was to evaluate normal Raman spectroscopy and SERS,

both in situ and by extraction. The efficiency of each technique was assessed in regards to the analysis of inks for use in the field of questioned documents. Efficiency was based on four factors: 1) ability to provide informative spectra 2) discriminating power 3) difficulty and 4) rapidity.

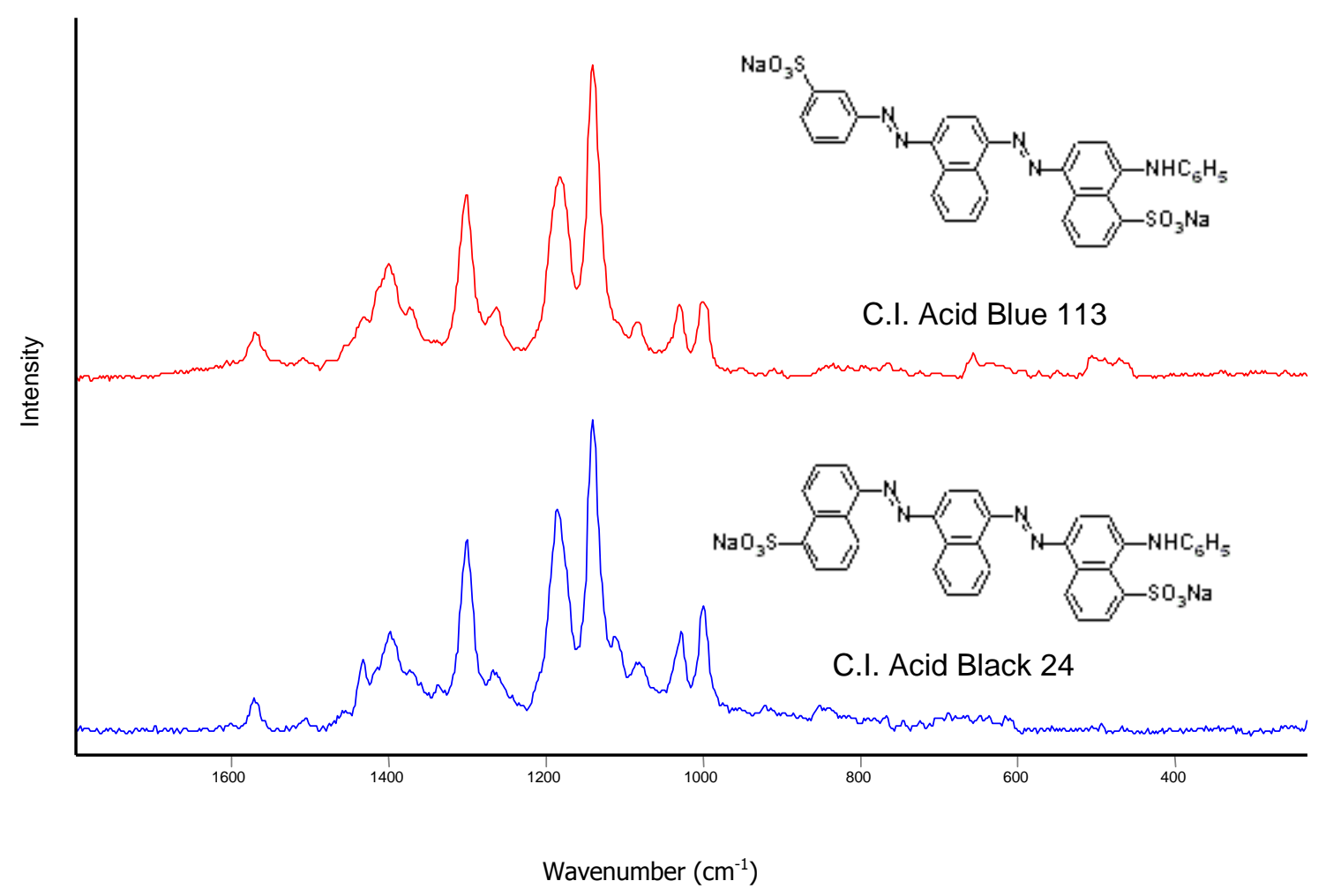

Figure 2: Raman spectra of the reference dye C.I. Acid Blue 113 (C.I. 26360) and C.I. Acid Black 24 (C.I. 42655) $\left(l_{\mathrm{ov} c}=785 \mathrm{~nm}\right)$. Courtesv of P. Buzzini

\section{METHODS}

Seventy-five powdered acid dyes from the ORCO Organic Dyestuffs Corporation (Concord, NC) were analyzed using normal Raman spectroscopy and SERS for the development of an acid dyes database (Appendix A). Preparation of the dyes and normal Raman spectroscopy were done as proposed by Buzzini (16). In order to avoid the problem of flooding the detector with signal, preparation of the acid dyes required the dilution of the powders with distilled water. 
The diluted acid dye samples were pipetted onto welled, glass slides covered with a small piece of aluminum foil to reduce interference from the glass. The excess distilled water was evaporated off using a hot plate. The samples were analyzed using normal Raman spectroscopy at 532nm and $785 \mathrm{~nm}$. The silver colloids used for the SERS techniques were prepared according to the method described by Lee and Meisel (17) with modifications by Leona (18). One hundred milligrams of silver nitrate were dissolved in $5 \mathrm{~mL}$ of cold distilled water in a $50 \mathrm{~mL}$ conical vial. $10 \%$ sulfuric acid was added dropwise to precipitate the silver sulfate. The precipitate was washed twice with distilled water and then dissolved in $580 \mathrm{~mL}$ of distilled water. Twenty-five milliliters of the silver sulfate solution were placed in a $50 \mathrm{~mL}$ conical vial with $2 \mathrm{~mL}$ of a $1 \% \mathrm{w}$ solution of glucose and $1 \mathrm{~mL}$ of a $1 \% \mathrm{w}$ solution of sodium citrate. The solution was vortexed and then heated for 30 seconds in a conventional microwave. The solution was heated additionally in 15 second increments as needed to achieve a UV-Vis spectrum with maximum absorption around $400 \mathrm{~nm}$. The solution was kept refrigerated and dark until use. For use, $1 \mathrm{~mL}$ of stock solution was centrifuged for 5 minutes at $16,060 \mathrm{x}$ g relative centrifugal force. Nine hundred fifty microliters of the supernatant were removed and replaced with distilled water. The silver colloids were added directly to the samples after normal Raman analysis was complete. SERS analysis was performed only at $532 \mathrm{~nm}$.

Thirty-one roller ball and ballpoint pens were collected for analysis (Appendix B). A pen mark from each pen was drawn onto a piece of printing paper. Each pen mark was analyzed at 532nm both in situ and through extraction using normal Raman and SERS. Extraction was carried out by the method used by Munro et al. (19). A small area of ink was scratched from the paper and placed into a vial containing methanol. The solution was vortexed and pipetted onto a welled, glass slide covered with a small piece of aluminum foil. The methanol was allowed to 
evaporate prior to analysis. The silver colloids were added directly to the samples after normal Raman analysis was complete.

Each analysis was performed three times, and an average spectrum was generated from these analyses. Acetaminophen was used as a positive control prior to each batch of analyses. Blanks of the paper, the methanol and the silver colloids were also analyzed as negative controls.

The Raman spectrometer used was a Bruker (Bruker Optik GmbH, Ettlingen, Germany), model Senterra, coupled to a Bruker BX51M microscope equipped with two lasers at $532 \mathrm{~nm}$ ( $20 \mathrm{~mW}$ power $)$ and $785 \mathrm{~nm}(\sim 100 \mathrm{~mW}$ power $)$ as excitation sources. A CCD camera was used as a detector.

Three objective lenses were available for the visualization of samples: 20x (about 5 microns spot size), 50x (about 2 microns spot size) and 100x (about 1-3 micron spot size). The display and management of data was carried out with OPUS Spectroscopy Software, v. 6.0, (Bruker Optik GmbH, Ettlingen, Germany).

\section{$\underline{\text { RESULTS }}$}

Table 1 shows the overall results of the acid dye analyses. The table indicates the total number of acid dyes in each dye color group and the number of usable spectra generated in each

\begin{tabular}{|c|c|c|c|c|}
\hline Nom C.I. & $\begin{array}{c}\text { \# of Acid } \\
\text { Dyes }\end{array}$ & NR@ 532nm & SERS@ 532nm & NR@785 nm \\
\hline Acid Black & 7 & 3 & 3 & 6 \\
\hline Acid Blue & 16 & 15 & 7 & 2 \\
\hline Acid Brown & 3 & 3 & 3 & 0 \\
\hline Acid Green & 4 & 3 & 2 & 0 \\
\hline Acid Orange & 5 & 4 & 4 & 0 \\
\hline Acid Red & 22 & 8 & 5 & 0 \\
\hline Acid Violet & 7 & 6 & 4 & 1 \\
\hline Acid Yellow & 11 & 2 & 4 & 9 \\
\hline Total & 75 & 44 & 32 & \\
\hline
\end{tabular}




\section{Table 1: Counts of usable spectra for each acid dye color group under the three analysis scenarios}

of the three analysis scenarios. Analysis at $785 \mathrm{~nm}$ with NR showed the best results for the acid black dyes. Figure 3 shows the spectra of Acid Black 63. Considerable fluorescence was observed at $785 \mathrm{~nm}$ in the acid blue dyes, and little to no signal was generated in the acid reds and yellows. Normal Raman at $532 \mathrm{~nm}$ generated good spectra in the acid blues. Figure 4

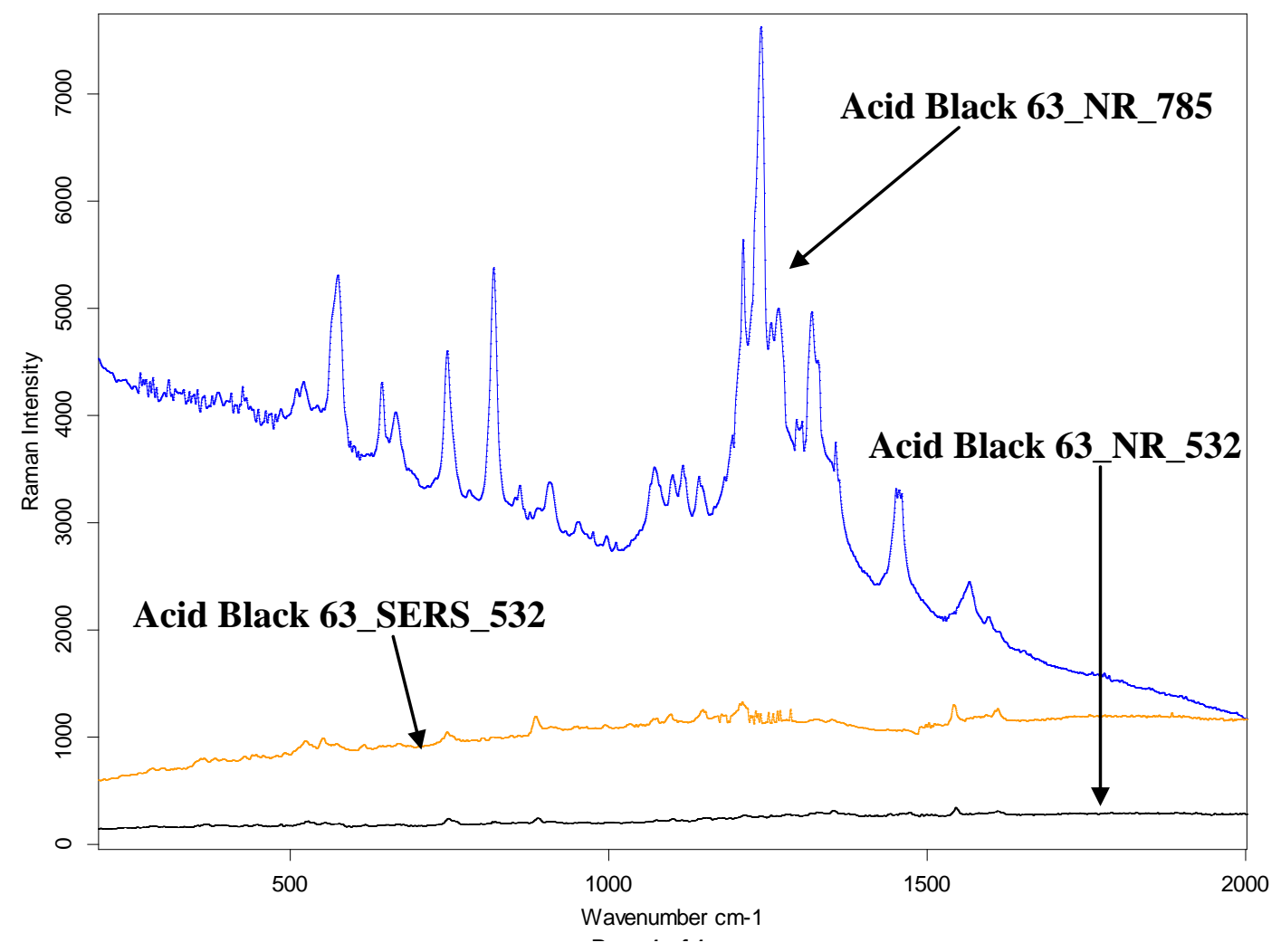

Figure 3: Acid Black 63 spectra using SERS at $532 \mathrm{~nm}$ and NR at both $532 \mathrm{~nm}$ and $785 \mathrm{~nm}$

shows three Acid Blue dyes analyzed at $532 \mathrm{~nm}$ using NR. The chemical structures $(20,21)$ for the each acid dye are also seen in Figure 4 along with peak assignment for some of the chemical bonds. The addition of the silver colloids at $532 \mathrm{~nm}$ showed signal enhancement and decreased fluorescence in some acid dyes compared to NR at $532 \mathrm{~nm}$. Figure 5 shows the fluorescence of Acid Yellow 19 using NR at $532 \mathrm{~nm}$ and the distinct spectra generated using SERS at $532 \mathrm{~nm}$. 
However, there were some instances, especially in the Acid Reds and Yellows, where SERS analysis increased the baseline or the fluorescence of the spectra.

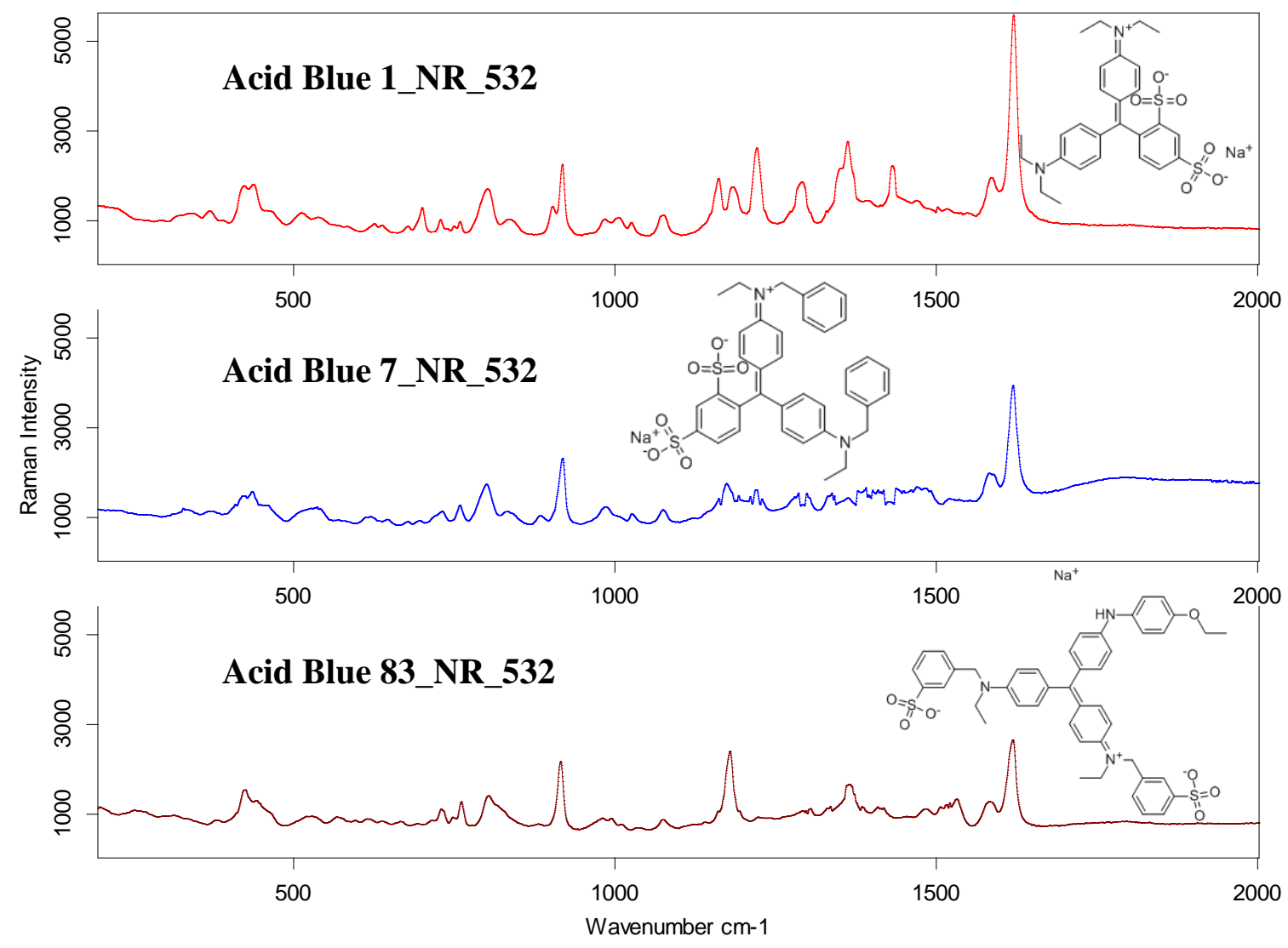

Figure 4: Three Acid Blue dyes analyzed at $532 \mathrm{~nm}$ using NR and their corresponding structures 


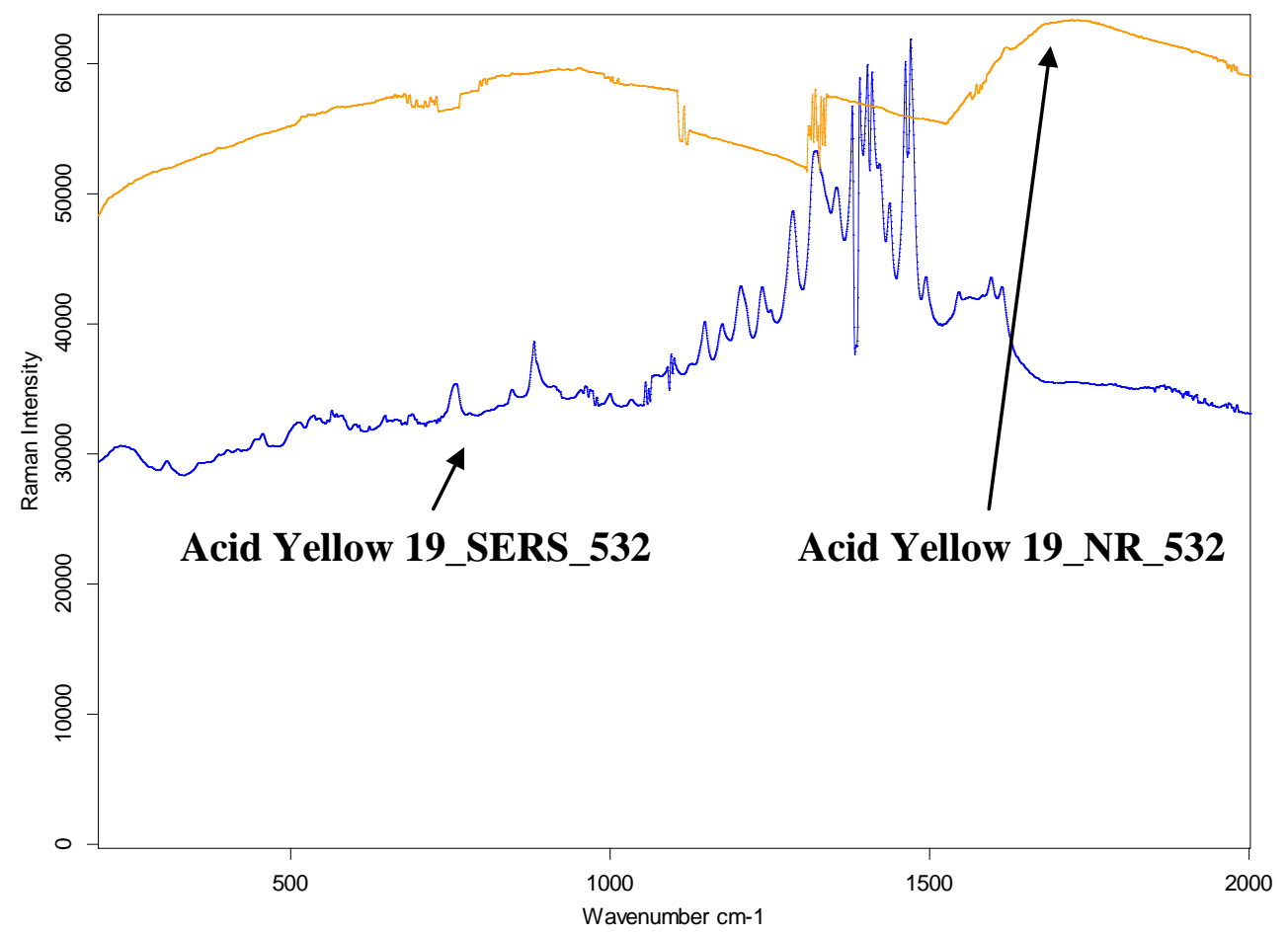

Figure 5: Acid Yellow 19 spectra at $532 \mathrm{~nm}$ using NR and SERS

Appendix $\mathrm{C}$ lists the seventy-five acid dyes and whether usable spectra were generated for each acid dye in each analysis scenario. Twenty-one of the acid dyes did not generate usable spectra using SERS or NR at both wavelengths. Thirteen of these were Acid Red dyes.

The count of usable spectra for each analysis method for the inks is shown in Table 2. Appendix D shows which scenarios gave usable spectra for each ink. Some peaks were visible

\begin{tabular}{|c|c|c|c|c|c|}
\hline $\begin{array}{c}\text { Pen } \\
\text { Brand }\end{array}$ & $\begin{array}{c}\text { \# of } \\
\text { pens }\end{array}$ & $\begin{array}{c}\text { in situ } \\
\text { NR }\end{array}$ & $\begin{array}{c}\text { in situ } \\
\text { SERS }\end{array}$ & $\begin{array}{c}\text { Extraction } \\
\text { NR }\end{array}$ & $\begin{array}{c}\text { Extraction } \\
\text { SERS }\end{array}$ \\
\hline Papermate & 7 & & \multicolumn{2}{|c}{} & 7 \\
\hline Uni-ball & 8 & 2 & 2 & & 6 \\
\hline Pilot & 4 & & \multicolumn{2}{|c|}{} & 3 \\
\hline Avery & 1 & & \multicolumn{2}{|c|}{} & 1 \\
\hline Zebra & 5 & 4 & 4 & 1 & 5 \\
\hline Parker & 2 & & \multicolumn{2}{|c|}{} & 2 \\
\hline BIC & 4 & 1 & & 1 & 4 \\
\hline Total & 31 & 7 & 6 & 2 & 28 \\
\hline
\end{tabular}

Table 2: Results of each analysis scenario for each pen brand 
through the fluorescence seen in the in situ NR analyses. Figure 6 shows an example of a spectrum generated in situ using NR. The results of the in situ SERS analyses did not show significant enhancement over the in situ NR analyses. The in situ SERS generated one less usable spectrum than the in situ NR. The fluorescence also increased with in situ SERS in some cases (Figure 7). Extraction with NR only produced two usable spectra. The most usable spectra were generated using extraction SERS. Thirteen inks that did not generate usable spectra using the other three methods produced usable spectra using the extraction SERS method. The three inks that did not generate usable spectra using extraction SERS were all from roller ball pens, and these inks did not produce usable spectra using any of the analysis methods.

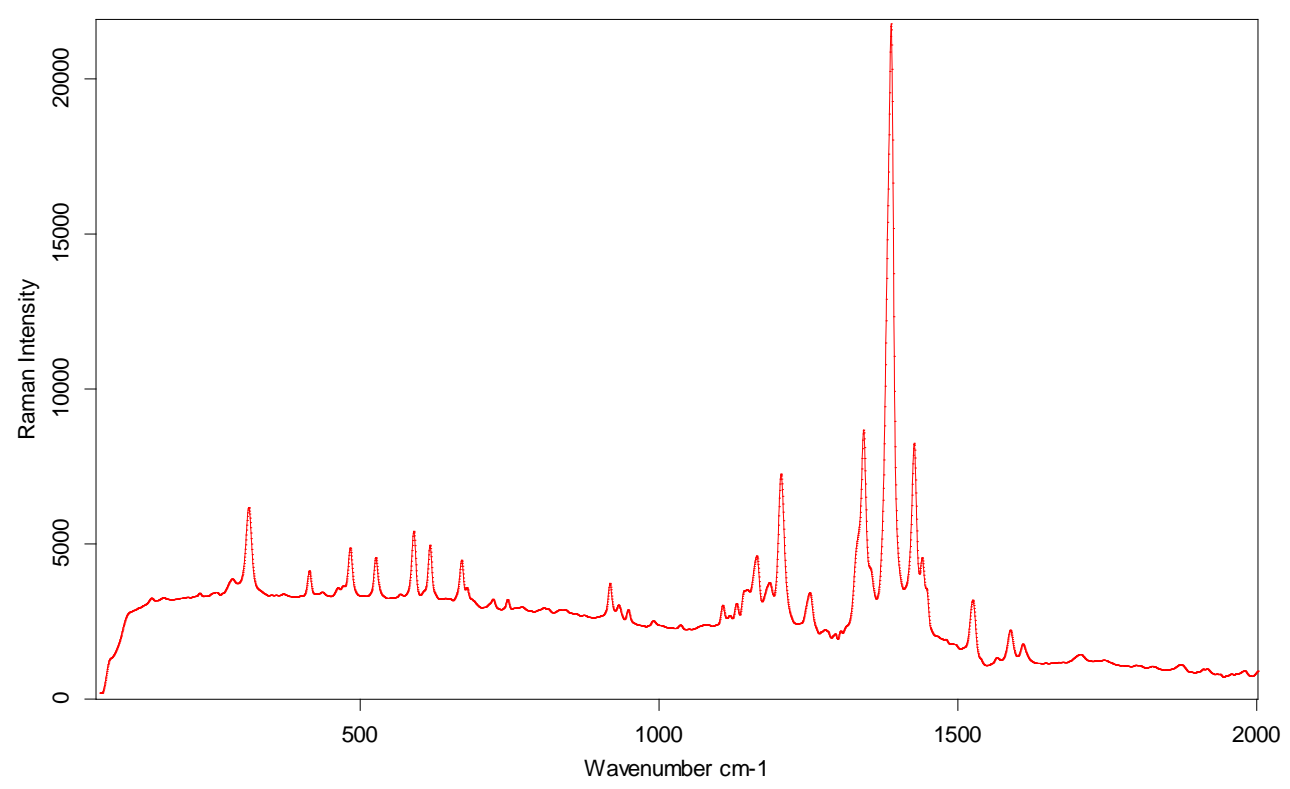

Figure 6: Test 18 in situ NR 


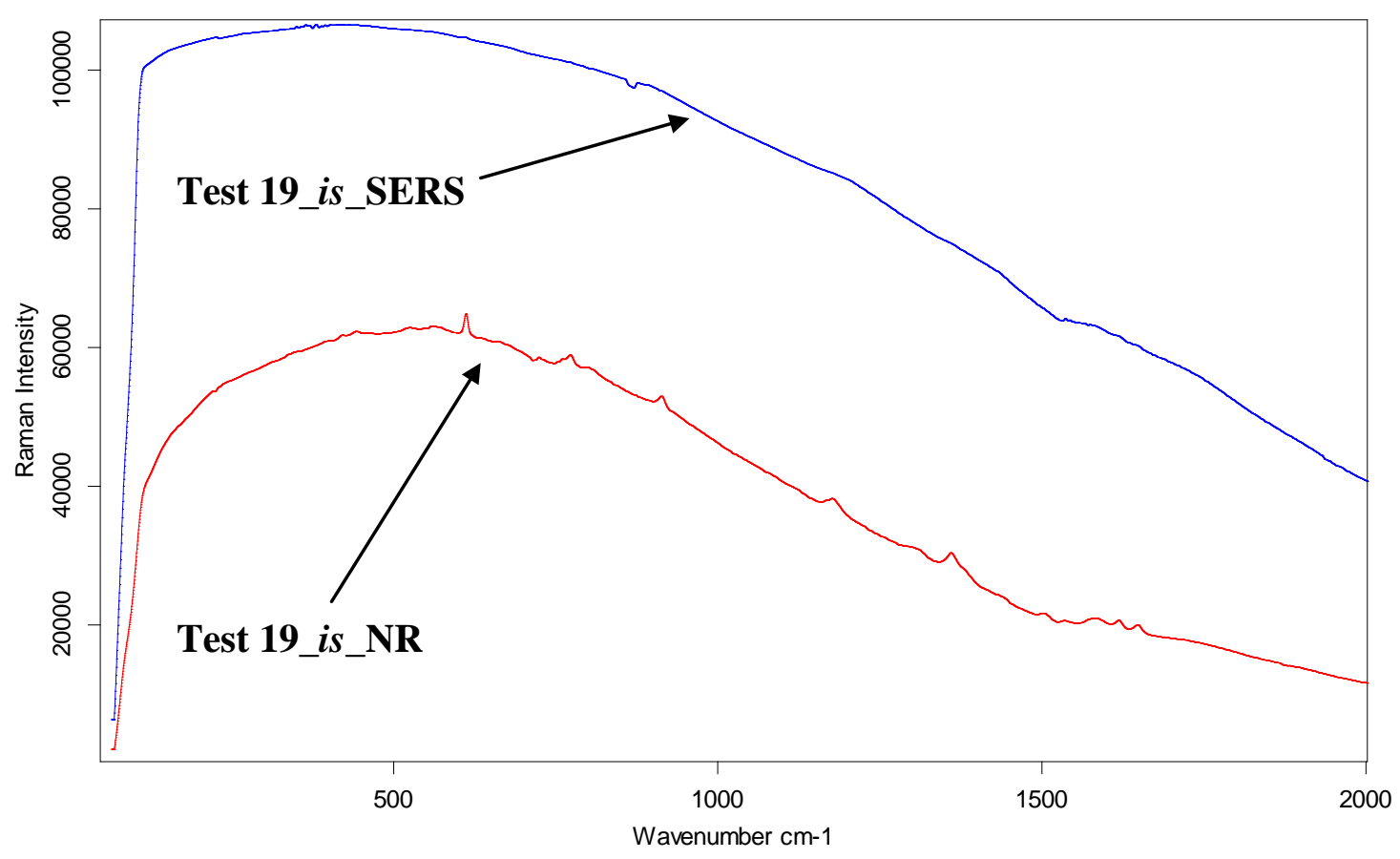

Figure 7: Example of increased fluorescence between in situ NR and SERS

Figure 8 shows an example of the difference in the spectra generated using NR and SERS after extraction. A number of the inks exhibited similar spectra when analyzed by extraction SERS (Figure 9). This same spectrum was also generated in some of the inks when analyzed in situ. Figure 10 shows the spectra for Test 19 analyzed in situ NR and SERS and extraction SERS. Similar peaks can be seen in all three spectra. Tests 15,16 and 18 generated this common spectrum under extraction SERS, however, this spectrum was different from the spectra generated using in situ NR and SERS for these three inks. The spectra for Test 18 using in situ NR and SERS and extraction SERS are seen in Figure 11. 


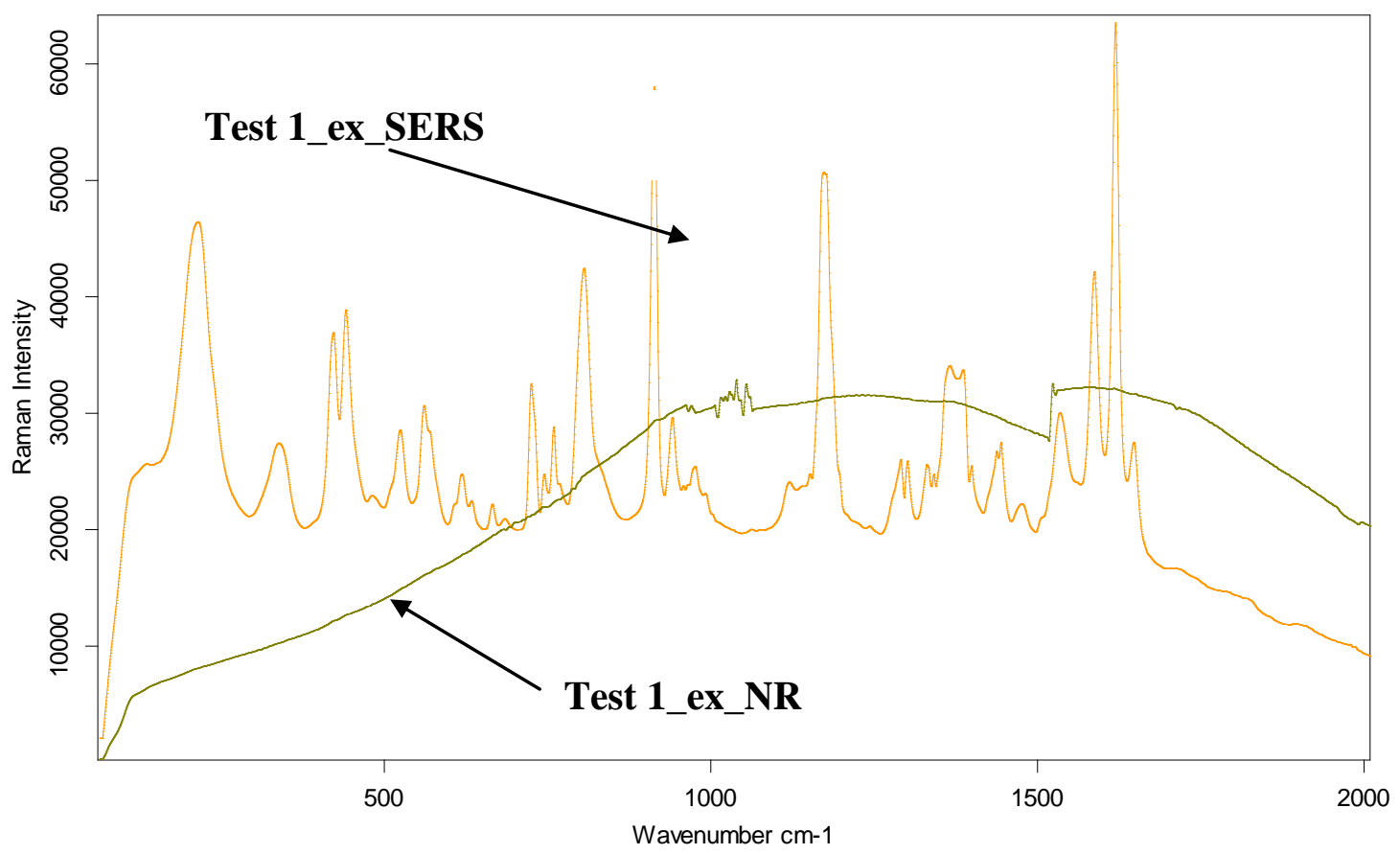

Figure 8: Spectra showing the difference between NR and SERS extraction

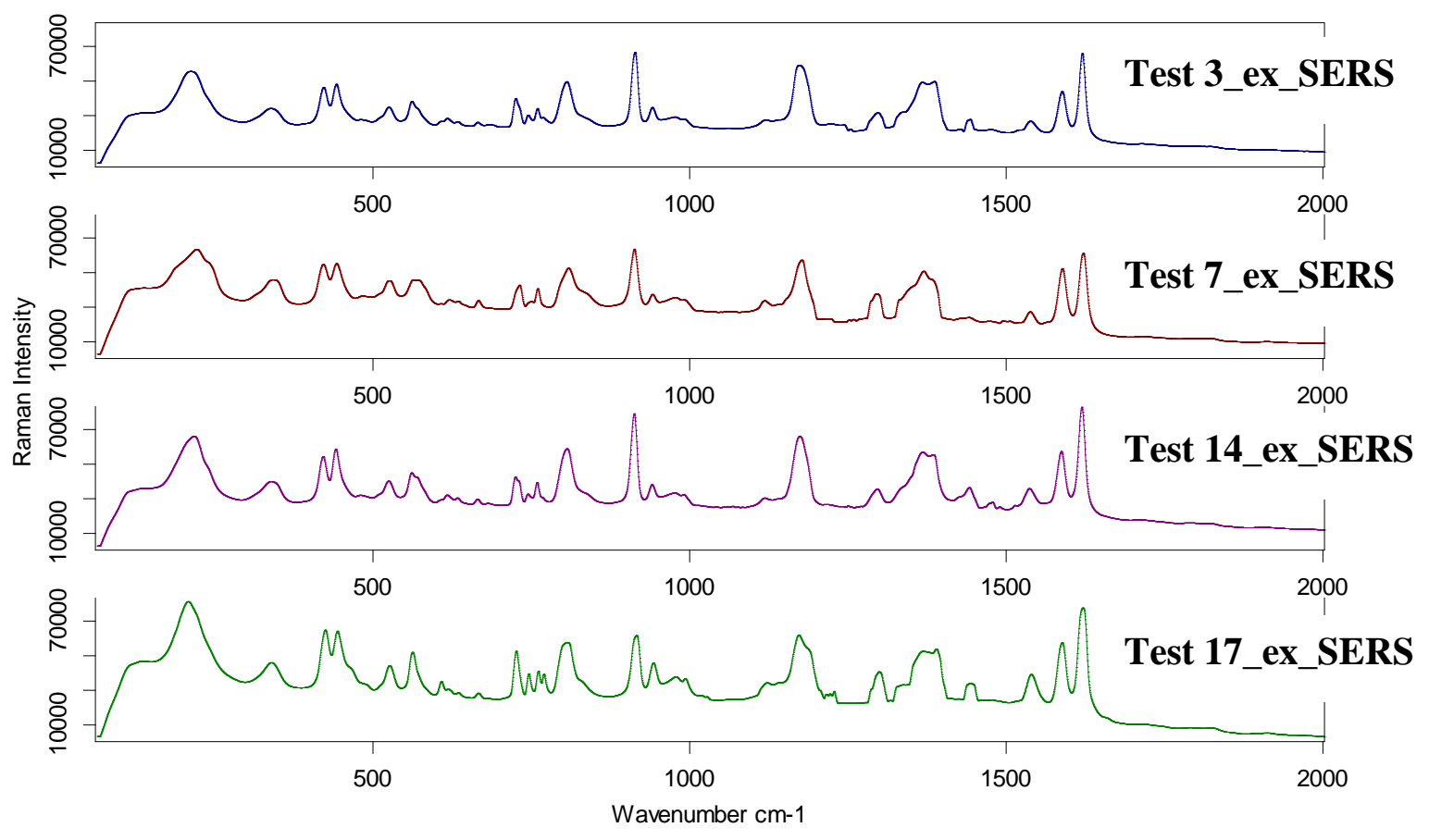

Figure 9: Four inks showing similar spectra analyzed using SERS extraction 


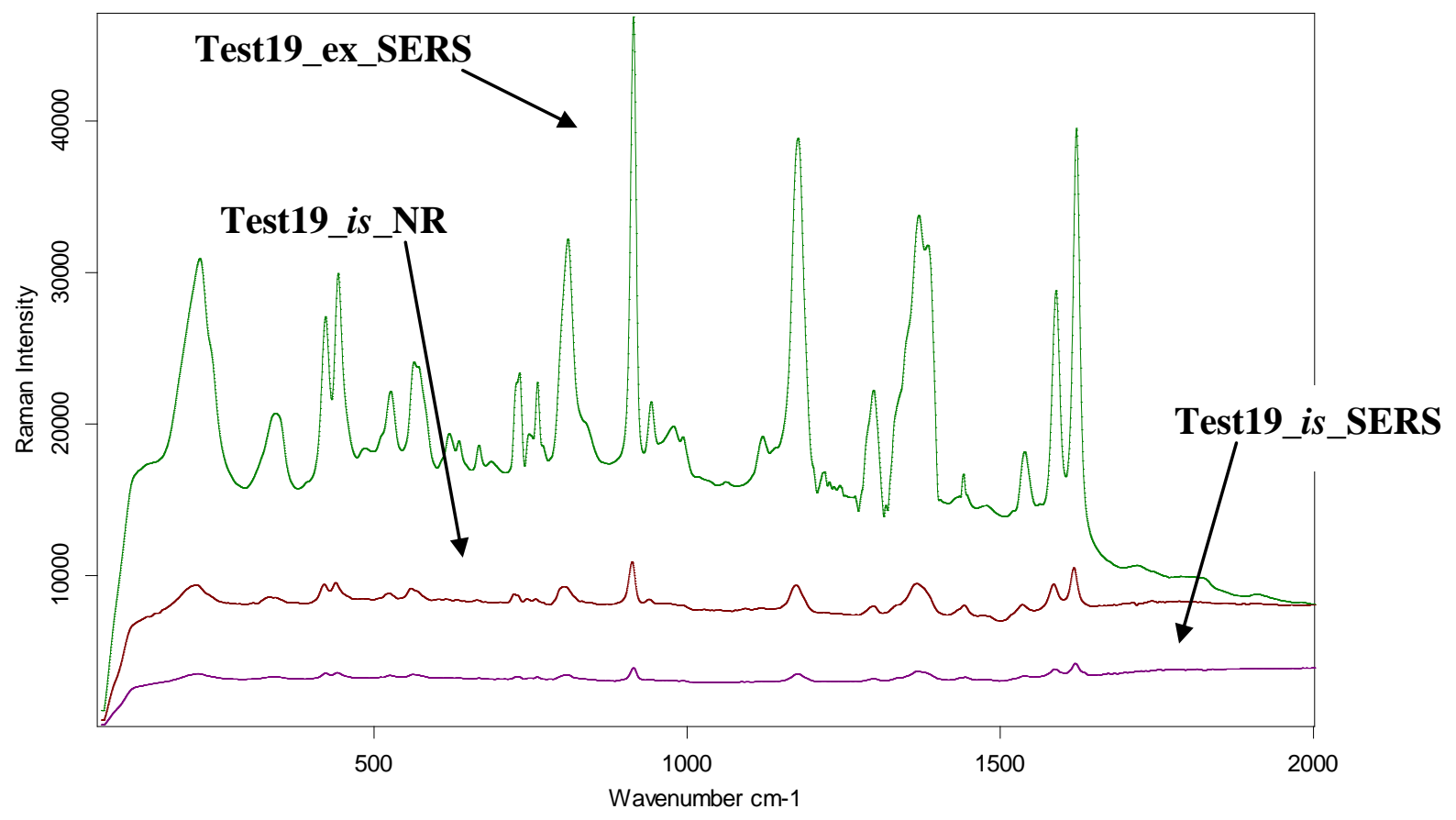

Figure 10: Spectra of Test 19 analyzed in situ NR and SERS and extraction SERS

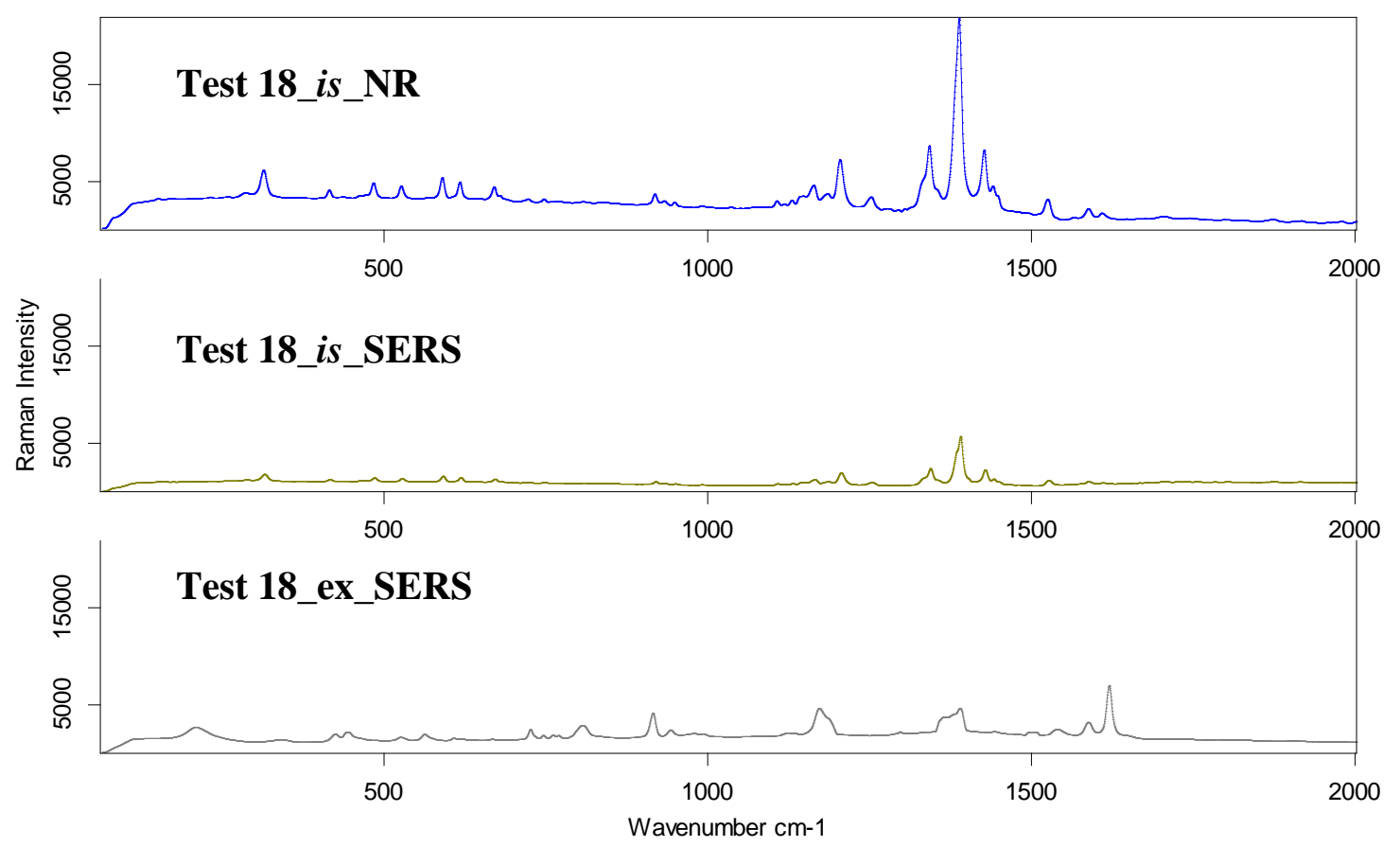

Figure 11: Spectra for Test 18 using in situ NR and SERS and extraction SERS 


\section{DISCUSSION}

The initial goal of this study, to build a spectral library, produced some challenges. The complexity of the chemical structures of the acid dyes is demonstrated in Figure $12(20,21)$. The inability of a single method to produce usable spectra for all the acid dyes may be explained by the variability in the chemical structures. The varying chemical structures make the availability of lasers with different wavelengths very important. Analysis using all three methods may be useful in order to determine which method works best for each acid dye. A specific dilution for the dyes would control the amount of dye in the samples and potentially decrease the amount of fluorescence with and without the SERS chemicals. The SERS effects might also be enhanced by concentrating the colloids and using an aggregating agent to facilitate the binding of the colloids to the dye compounds.<smiles>O=[N+]([O-])c1ccc2c(N=Nc3c(O)ccc4ccccc34)c(O)cc(S(=O)(=O)[O-])c2c1</smiles>

Acid Black 52

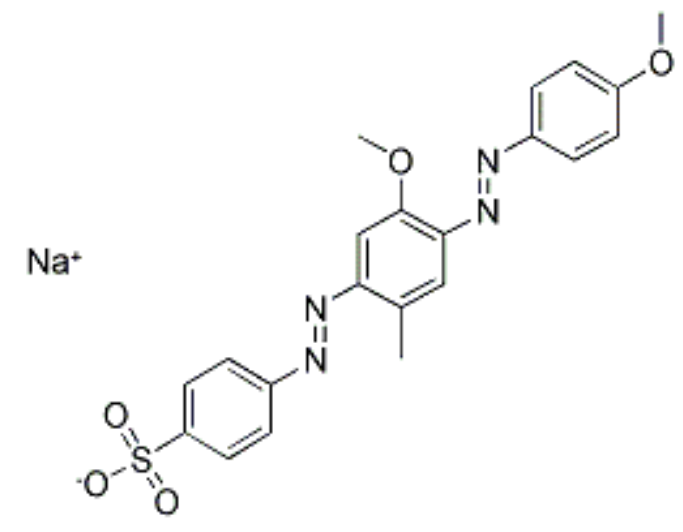

Acid Orange 156

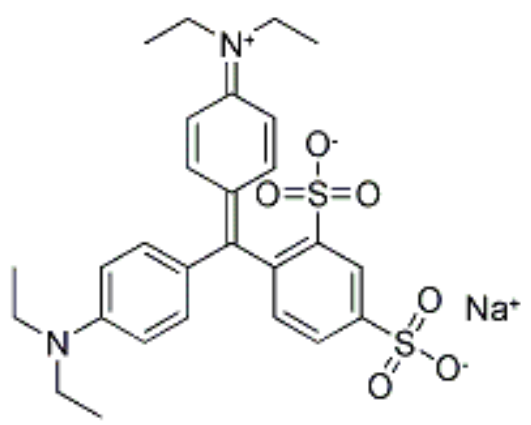

Acid Blue 1 


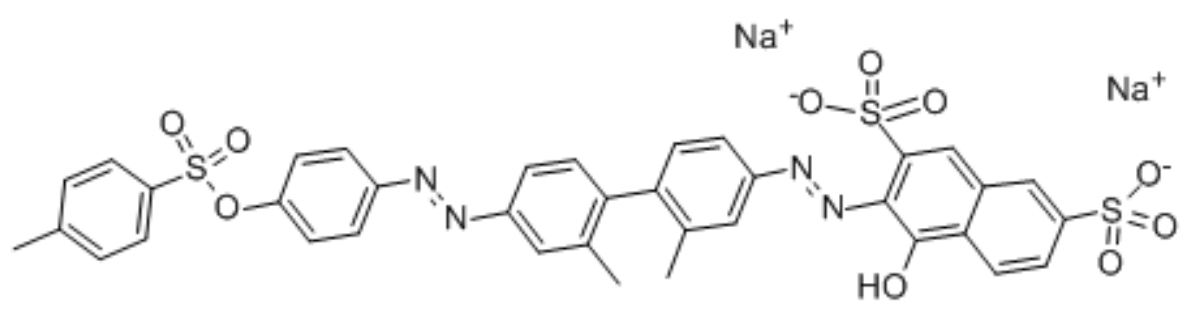

Acid Red 111

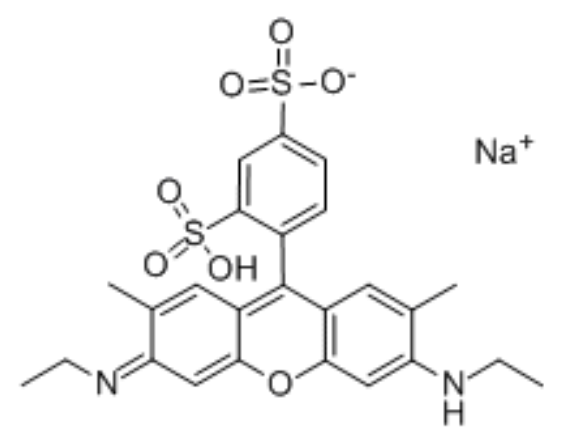

Acid Red 50

\section{Figure 12: Chemical structure of five acid dyes}

Ink analysis using NR and SERS in situ and by extraction was the second focus of this study. The inks that did not generate usable spectra or that gave varying spectra depending on the analysis method were all from roller ball pens. The components of roller ball pen ink may require a different method for analysis to obtain more consistent results. Ink analysis may also benefit from the concentration of the colloids and the use of an aggregating agent. Adding these two steps may increase the effectiveness of the method in situ. This would help to avoid destruction of the sample. Analysis of the inks first by TLC and then analysis of each spot using SERS may help to determine which dye spot is being seen in the spectra using the extraction SERS method.

The common spectrum seen in the extraction SERS analysis of the inks can be explained for some of the inks due to the pens being the same brand. However, another situation arose where three inks, all from roller ball pens, generated different spectra depending on if the ink 
was analyzed in situ or by extraction. When the three inks were analyzed using extraction, the spectra produced were the common spectrum. This indicates that a particular component of the inks is being extracted and enhanced by the SERS chemicals.

The inter- and intra-variability of the dye and ink samples become key in determining whether analysis using NR or SERS is useful. The intra-variability needs to be small enough to have reproducible spectra, while the inter-variability needs to be large enough to allow for differentiation between spectra from different samples. Further research into the statistical analysis of both inter- and intra-variability of the spectra will be useful in determining the discriminating power of the method (22).

\section{CONCLUSION}

The similarity of some of the spectra produced using extraction SERS makes differentiation extremely subjective. The dilemma comes in determining how different the spectra have to be to be considered different inks, and vice versa, how similar the spectra have to be to be considered the same ink. The results showed the definite potential for SERS to produce enhanced spectra over NR, but the inability to differentiate between the spectra produced makes the enhancement of little value. Further research needs to be done into the chemical structures of the acid dyes and the components that make up the ballpoint and roller ball inks. The chemical structures should also be looked at in conjunction with the peaks of the spectra to determine which bonds are represented. Concentration of the silver colloids and the use of an aggregating agent should also be investigated as potential ways to increase the effects of the SERS methods. With continued research, SERS may become a useful method of analysis for inks within the field of questioned documents. 


\section{BIBLIOGRAPHY}

1. Smith E, Dent G. Modern Raman Spectroscopy: A Practical Approach. West Sussex, England: John Wiley \& Sons Ltd, 2005.

2. Koenig JL. Spectroscopy of Polymers. Washington, D.C. : American Chemical Society, 1992.

3. Fleischmann M, Hendra PJ, McQuillan AJ. Raman Spectra of Pyridine Adsobred at a Silver Electrode. Chemical Physics Letters. 1974;26(2):163-6.

4. Campion A, Kambhampati P. Surface-enhanced Raman Scattering. Chemical Society Reviews. 1998;27:241-50.

5. Lombardi JR, Birke RL. A Unified Approach to Surface-Enhanced Raman Spectroscopy. Journal of Physical Chemistry. 2008;112(14):5605-17.

6. Lombardi JR, Birke RL, Lu T, Xu J. Charge-transfer theory of surface enhanced Raman spectroscopy: Herzberg-Teller contributions. Journal of Chemical Physics. 1986 April 1986;84(8):4174-80.

7. White PC. SERRS Spectroscopy - a new technique for forensic science? Science \& Justice. 2000;40(2):113-9.

8. American Society for Testing and Materials. E 444-06.

9. Ifa DR, Gumaelius LM, Eberlin LS, Manicke NE, Cooks RG. Forensic analysis of inks by imaging desorption electrospray ionization (DESI) mass spectrometry. The Analyst. 2007; 132:461-7.

10. Siegel J, Allison J, Mohr D, Dunn J. The use of laser desoprtion/ionization mass spectrometry in the analysis of inks in questioned documents. Talanta. 200515 August 2005;67(2):425-9.

11. Weyermann C, Kirsch D, Costa-Vera C, Spengler B. Photofading of Ballpoint Dyes Studied on Paper by LDI and MALDI MS. Journal of the American Society for Mass Spectrometry. 2006 March 2006;17(3):297-306.

12. Weyermann C, Kirsch D, Costa-Vera C, Spengler B. A GC/MS study of the drying of ballpoint pen ink on paper. Forensic Science International. 2007;168:119-27.

13. Kunicki M. Differentiating blue ballpoint pen inks. Problems of Forensic Sciences. 2002:56-70.

14. Mazzella WD, Buzzini P. Raman spectroscopy of blue gel pen inks. Forensic Science International. 2005;152:241-. 
15. Geiman I, Leona M, Lombardi JR. Application of Raman Spectroscopy and SurfaceEnhanced Raman Scattering to the Analysis of Synthetic Dyes Found in Ballpoint Pen Inks. Journal of Forensic Sciences. 2009 July 2009;54(4):947-52.

16. Buzzini P. L'application de la spectroscopie Raman en criminalistique pour l'analyse du colorant des fibres textiles en acrylique, coton et laine. Dorigny, Switzerland: University of Lausanne, 2007.

17. Lee PC, Meisel D. Adsorption and Surface-Enhanced Raman of Dyes on Silver and Gold Sols. Journal of Physical Chemistry. 1982;86(17):3391-5.

18. Leona M. Microanalysis of organic pigments and glazes in polychrome works of art by surface-enhanced resonance Raman scattering. Proceedings of the National Academy of Sciences. 2009 June 25, 2009:1-6.

19. Munro CH, Smith WE, White PC. Qualitative and Semi-quantitative Trace Analysis of Acidic Monoazo Dyes by Surface Enhanced Resonance Raman Scattering. Analyst. 1995 April 1995;120:993-1003.

20. Society of Dyers and Colourists. Colour Index International Heritage Edition. England; 2008.

21. ChemicalBook Inc. 23 March 2012. http://www.chemicalbook.com.

22. Weyermann, C., Bucher, L., Majcherczyk, P. A statistical methodology for the comparison of blue gel pen inks analyzed by laser desorption/ionization mass spectrometry. Science \& Justice. 2011; 51:122-130. 


\section{APPENDIX A}

\begin{tabular}{|l|l|}
\hline Nom C.I. & Commercial Name \\
\hline Acid Black 107 & ORCOLAN Neutral Black BGL 200\% \\
Acid Black 164 & ORCOLAN Neutral Black 3SBR \\
Acid Black 172 & ORCOLAN Neutral Black DW \\
Acid Black 2 & ORCOACID Nigrosine Jet L \\
Acid Black 52 & ORCOLAN Fast Black WAN EX \\
Acid Black 60 & ORCOLAN Neutral Grey B \\
Acid Black 63 & ORCOLAN Fast Black BN Ex Conc \\
Acid Blue 1 & ORCOACID Blue V Ex Conc \\
Acid Blue 127 & ORCOLAN Neutral Blue GL \\
Acid Blue 158 & ORCOLAN Fast Blue GGN 200\% \\
Acid Blue 182 & ORCOACID Alizarine Light Blue HRL \\
Acid Blue 193 & ORCOLAN Neutral Dark Blue BR \\
Acid Blue 25 & ORCOACID Alizarine Fast Blue SWA \\
Acid Blue 260 & ORCO NYLOSOL Brilliant Blue RL 200\% \\
Acid Blue 281 & ORCO NYLOSOL Blue GLF \\
Acid Blue 324 & ORCO NYLOSOL Blue BRL 200\% \\
Acid Blue 40 & ORCOACID Sapphire 2GL 200\% \\
Acid Blue 41 & ORCOACID Blue ARA \\
Acid Blue 45 & ORCOACID Blue SAP \\
Acid Blue 62 & ORCOACID Brilliant Alizarine Blue R 150\% \\
Acid Blue 7 & ORCOACID Blue A 150\% \\
Acid Blue 83 & ORCO MILLING Brilliant Cyanine 6B \\
Acid Blue 90 & ORCO MILLING Brilliant Cyanine G \\
Acid Brown 19 & ORCO NYLOSOL Brown \\
Acid Brown 282 & ORCOLAN Neutral Brown GRS \\
Acid Brown 289 & ORCOLAN Neutral Brown BRL \\
Acid Green 16 & ORCOACID Napthalamine Green 2G 300\% \\
Acid Green 20 & ORCOACID Dark Green A Conc \\
Acid Green 28 & ORCO NYLOSOL Green C3G \\
Acid Green 9 & ORCOACID Fast Green B \\
Acid Orange 116 & ORCO NYLOSOL Orange SLF 200\% \\
Acid Orange 156 & ORCO NYLOSOL Orange 3G Conc \\
Acid Orange 60 & ORCOLAN Neutral Orange NR \\
Acid Orange 74 & ORCOLAN Fast Orange GEN \\
Acid Orange 86 & ORCOLAN Neutral Orange RL 250\% \\
Acid Red 1 & ORCOACID Phloxine GR 175\% \\
Acid Red 111 & ORCO NYLOSOL Scarlet GN \\
Acid Red 114 & ORCO MILLING Red RS 125\% \\
Acid Red 119 & ORCO MILLING Bordeaux LFS \\
Acid Red 131 151 & ORCO MILLING Brilliant Red 3NR \\
\hline
\end{tabular}




\begin{tabular}{|ll|}
\hline Acid Red 18 & ORCOACID Brilliant Scarlet 3R-L \\
Acid Red 182 & ORCOLAN Neutral Red B \\
Acid Red 186 & ORCOLAN Fast Pink BN Conc \\
Acid Red 194 & ORCOLAN Fast Bordeaux RL \\
Acid Red 249 & ORCO MILLING Brilliant Red B \\
Acid Red 266 & ORCO NYLOSOL Red 2GP (N) \\
Acid Red 299 & ORCO NYLOSOL Rubine 5BLF (N) \\
Acid Red 337 & ORCO NYLOSOL Red GN 200\% \\
Acid Red 4 & ORCOACID Eosine G \\
Acid Red 414 & ORCOLAN Neutral Red RLS \\
Acid Red 50 & ORCOACID Sulpho Rhodamine G \\
Acid Red 57 & ORCOACID Rubine 3GP \\
Acid Red 73 & ORCOACID Scarlet MR \\
Acid Red 88 & ORCOACID Fast Red A Conc \\
Acid Violet 1 & ORCOACID Violet 2R Conc \\
Acid Violet 12 & ORCOACID Carmine 4B Conc \\
Acid Violet 17 & ORCOACID Violet 4B \\
Acid Violet 43 & ORCOACID Violet WN \\
Acid Violet 48 & ORCO MILLING Brilliant Violet BL 200\% \\
Acid Violet 7 & ORCOACID Fuchsine 6B Ex Conc \\
Acid Violet 90 & ORCOLAN Neutral Bordeaux BSB \\
Acid Yellow 127 & ORCO NYLOSOL Brilliant Yellow 5G \\
Acid Yellow 129 & ORCOLAN Neutral Yellow 2GL Ex \\
Acid Yellow 151 & ORCOLAN Neutral Yellow WN 250\% \\
Acid Yellow 17 & ORCOACID Fast Light Yellow 2G \\
Acid Yellow 184 & ORCOACID Brilliant Flavine 8GN \\
Acid Yellow 19 & ORCOACID Fast Light Yellow R \\
Acid Yellow 219 & ORCO NYLOSOL Yellow 4GR 250\% (N) \\
Acid Yellow 250 & ORCO NYLOSOL Yellow Brillant FSC \\
Acid Yellow 38 & ORCO MILLING Yellow O \\
Acid Yellow 49 & ORCO NYLOSOL Yellow 9GL 200\% \\
Acid Yellow 99 & ORCOACID Fast Yellow GRN \\
\hline & \\
\end{tabular}




\section{APPENDIX B}

\begin{tabular}{|c|c|c|c|}
\hline Pen Number & Pen Brand & Pen Type & Ink Color \\
\hline 1 & $\begin{array}{l}\text { Papermate } \\
\text { Comfortmate }\end{array}$ & Ballpoint & Black \\
\hline 2 & Papermate Ball Point & Ballpoint & Black \\
\hline 3 & Papermate PhD & Ballpoint & Black \\
\hline 4 & Papermate PhD Multi & Ballpoint & Black \\
\hline 5 & Uni-ball Vision Micro & Roller ball & Black \\
\hline 6 & Uni-ball Vision Fine & Roller ball & Black \\
\hline 7 & Uni Power Take 1.0 & Ballpoint & Black \\
\hline 8 & $\begin{array}{l}\text { Pilot Precise Rolling } \\
\text { Ball V5 Extra-Fine }\end{array}$ & Roller ball & Black \\
\hline 9 & Pilot Dr. Grip & Ballpoint & Black \\
\hline 10 & Pilot Dr. Grip & Ballpoint & Black \\
\hline 11 & AVERY Triple Click & Ballpoint & Black \\
\hline 12 & Zebra F-301 & Ballpoint & Black \\
\hline 13 & Parker & Ballpoint & Black \\
\hline 14 & $\begin{array}{c}\text { Papermate } \\
\text { Comfortmate } \\
\end{array}$ & Ballpoint & Blue \\
\hline 15 & Uni-ball Vision Micro & Roller ball & Blue \\
\hline 16 & Uni-ball Vision Fine & Roller ball & Blue \\
\hline 17 & Uni Power Tank 1.0 & Ballpoint & Blue \\
\hline 18 & Zebra GR8 Roller 0.7 & Roller ball & Blue \\
\hline 19 & Zebra F-301 & Ballpoint & Blue \\
\hline 20 & Parker & Ballpoint & Blue \\
\hline 21 & $\begin{array}{c}\text { Papermate } \\
\text { Comfortmate }\end{array}$ & Ballpoint & Red \\
\hline 22 & $\begin{array}{l}\text { Papermate } \\
\text { Comfortmate }\end{array}$ & Ballpoint & Red \\
\hline 23 & Uni-ball Vision Fine & Roller ball & Red \\
\hline 24 & $\begin{array}{l}\text { Pilot Precise Rolling } \\
\text { Ball V5 Extra Fine }\end{array}$ & Roller ball & Red \\
\hline 25 & Uni-ball Vision Fine & Roller ball & Purple \\
\hline 26 & BIC Multi-Color & Ballpoint & Black \\
\hline 27 & BIC Multi-Color & Ballpoint & Green \\
\hline 28 & BIC Multi-Color & Ballpoint & Blue \\
\hline 29 & BIC Multi-Color & Ballpoint & Red \\
\hline
\end{tabular}




\begin{tabular}{|c|c|c|c|}
\hline 30 & Zebra Clip-On 2-Color & Ballpoint & Black \\
\hline 31 & Zebra Clip-On 2-Color & Ballpoint & Red \\
\hline
\end{tabular}


APPENDIX C

\begin{tabular}{|c|c|c|c|}
\hline Nom C.I. & NR @ 532nm & SERS @ 532nm & NR@785 nm \\
\hline Acid Black 107 & $\mathrm{~N}$ & $\mathrm{~N}$ & $\mathrm{Y}$ \\
\hline Acid Black 164 & $\mathrm{~N}$ & $\mathrm{~N}$ & $\mathrm{Y}$ \\
\hline Acid Black 172 & $\mathrm{Y}$ & $\mathrm{Y}$ & $\mathrm{Y}$ \\
\hline Acid Black 2 & $\mathrm{Y}$ & $\mathrm{Y}$ & $\mathrm{N}$ \\
\hline Acid Black 52 & $\mathrm{Y}$ & $\mathrm{Y}$ & $\mathrm{Y}$ \\
\hline Acid Black 60 & $\mathrm{~N}$ & $\mathrm{~N}$ & $\mathrm{Y}$ \\
\hline Acid Black 63 & $\mathrm{~N}$ & $\mathrm{~N}$ & $\mathrm{Y}$ \\
\hline Acid Blue 1 & $\mathrm{Y}$ & $\mathrm{N}$ & $\mathrm{N}$ \\
\hline Acid Blue 127 & $\mathrm{Y}$ & $\mathrm{N}$ & $\mathrm{N}$ \\
\hline Acid Blue 158 & $\mathrm{Y}$ & $\mathrm{Y}$ & $\mathrm{Y}$ \\
\hline Acid Blue 182 & $\mathrm{Y}$ & $\mathrm{N}$ & $\mathrm{N}$ \\
\hline Acid Blue 193 & $\mathrm{Y}$ & $\mathrm{Y}$ & $\mathrm{Y}$ \\
\hline Acid Blue 25 & $\mathrm{Y}$ & $\mathrm{N}$ & $\mathrm{N}$ \\
\hline Acid Blue 260 & $\mathrm{Y}$ & $\mathrm{Y}$ & $\mathrm{N}$ \\
\hline Acid Blue 281 & $\mathrm{Y}$ & $\mathrm{N}$ & $\mathrm{N}$ \\
\hline Acid Blue 324 & $\mathrm{~N}$ & $\mathrm{~N}$ & $\mathrm{~N}$ \\
\hline Acid Blue 40 & $\mathrm{Y}$ & $\mathrm{Y}$ & $\mathrm{N}$ \\
\hline Acid Blue 41 & $\mathrm{Y}$ & $\mathrm{Y}$ & $\mathrm{N}$ \\
\hline Acid Blue 45 & $\mathrm{Y}$ & $\mathrm{N}$ & $\mathrm{N}$ \\
\hline Acid Blue 62 & $\mathrm{Y}$ & $\mathrm{N}$ & $\mathrm{N}$ \\
\hline Acid Blue 7 & $\mathrm{Y}$ & $\mathrm{N}$ & $\mathrm{N}$ \\
\hline Acid Blue 83 & $\mathrm{Y}$ & $\mathrm{Y}$ & $\mathrm{N}$ \\
\hline Acid Blue 90 & $\mathrm{Y}$ & $\mathrm{Y}$ & $\mathrm{N}$ \\
\hline Acid Brown 19 & $\mathrm{Y}$ & $\mathrm{Y}$ & $\mathrm{N}$ \\
\hline Acid Brown 282 & $\mathrm{Y}$ & $\mathrm{Y}$ & $\mathrm{N}$ \\
\hline Acid Brown 289 & $y$ & $\mathrm{Y}$ & $\mathrm{N}$ \\
\hline Acid Green 16 & $\mathrm{Y}$ & $\mathrm{Y}$ & $\mathrm{N}$ \\
\hline Acid Green 20 & $\mathrm{Y}$ & $\mathrm{N}$ & $\mathrm{N}$ \\
\hline Acid Green 28 & $\mathrm{Y}$ & $\mathrm{N}$ & $\mathrm{N}$ \\
\hline Acid Green 9 & $\mathrm{~N}$ & $\mathrm{Y}$ & $\mathrm{N}$ \\
\hline Acid Orange 116 & $\mathrm{Y}$ & $\mathrm{Y}$ & $\mathrm{N}$ \\
\hline Acid Orange 156 & $\mathrm{~N}$ & $\mathrm{~N}$ & $\mathrm{~N}$ \\
\hline Acid Orange 60 & $\mathrm{Y}$ & $\mathrm{Y}$ & $\mathrm{N}$ \\
\hline Acid Orange 74 & $\mathrm{Y}$ & $\mathrm{Y}$ & $\mathrm{N}$ \\
\hline Acid Orange 86 & $\mathrm{Y}$ & $\mathrm{Y}$ & $\mathrm{N}$ \\
\hline Acid Red 1 & $\mathrm{Y}$ & $\mathrm{N}$ & $\mathrm{N}$ \\
\hline Acid Red 111 & $\mathrm{~N}$ & $\mathrm{~N}$ & $\mathrm{~N}$ \\
\hline Acid Red 114 & $\mathrm{~N}$ & $\mathrm{~N}$ & $\mathrm{~N}$ \\
\hline
\end{tabular}




\begin{tabular}{|c|c|c|c|}
\hline Acid Red 119 & $\mathrm{~N}$ & $\mathrm{~N}$ & $\mathrm{~N}$ \\
\hline Acid Red 131 & $\mathrm{~N}$ & $\mathrm{~N}$ & $\mathrm{~N}$ \\
\hline Acid Red 138 & $\mathrm{~N}$ & $\mathrm{~N}$ & $\mathrm{~N}$ \\
\hline Acid Red 14 & $\mathrm{~N}$ & $\mathrm{~N}$ & $\mathrm{~N}$ \\
\hline Acid Red 151 & $\mathrm{~N}$ & $\mathrm{Y}$ & $\mathrm{N}$ \\
\hline Acid Red 18 & $\mathrm{~N}$ & $\mathrm{~N}$ & $\mathrm{~N}$ \\
\hline Acid Red 182 & $\mathrm{Y}$ & $\mathrm{Y}$ & $\mathrm{N}$ \\
\hline Acid Red 186 & $\mathrm{Y}$ & $\mathrm{Y}$ & $\mathrm{N}$ \\
\hline Acid Red 194 & $\mathrm{Y}$ & $\mathrm{Y}$ & $\mathrm{N}$ \\
\hline Acid Red 249 & $\mathrm{~N}$ & $\mathrm{~N}$ & $\mathrm{~N}$ \\
\hline Acid Red 266 & $\mathrm{Y}$ & $\mathrm{N}$ & $\mathrm{N}$ \\
\hline Acid Red 299 & $\mathrm{~N}$ & $\mathrm{~N}$ & $\mathrm{~N}$ \\
\hline Acid Red 337 & $\mathrm{Y}$ & $\mathrm{N}$ & $\mathrm{N}$ \\
\hline Acid Red 4 & $\mathrm{~N}$ & $\mathrm{~N}$ & $\mathrm{~N}$ \\
\hline Acid Red 414 & $\mathrm{Y}$ & $\mathrm{Y}$ & $\mathrm{N}$ \\
\hline Acid Red 50 & $\mathrm{~N}$ & $\mathrm{~N}$ & $\mathrm{~N}$ \\
\hline Acid Red 57 & $\mathrm{Y}$ & $\mathrm{N}$ & $\mathrm{N}$ \\
\hline Acid Red 73 & $\mathrm{~N}$ & $\mathrm{~N}$ & $\mathrm{~N}$ \\
\hline Acid Red 88 & $\mathrm{~N}$ & $\mathrm{~N}$ & $\mathrm{~N}$ \\
\hline Acid Violet 1 & $\mathrm{Y}$ & $\mathrm{Y}$ & $\mathrm{N}$ \\
\hline Acid Violet 12 & $\mathrm{Y}$ & $\mathrm{N}$ & $\mathrm{N}$ \\
\hline Acid Violet 17 & $\mathrm{Y}$ & $\mathrm{Y}$ & $\mathrm{N}$ \\
\hline Acid Violet 43 & $\mathrm{Y}$ & $\mathrm{Y}$ & $\mathrm{N}$ \\
\hline Acid Violet 48 & $\mathrm{~N}$ & $\mathrm{~N}$ & $\mathrm{~N}$ \\
\hline Acid Violet 7 & $\mathrm{Y}$ & $\mathrm{N}$ & $\mathrm{N}$ \\
\hline Acid Violet 90 & $\mathrm{Y}$ & $\mathrm{Y}$ & $\mathrm{N}$ \\
\hline Acid Yellow 127 & $\mathrm{~N}$ & $\mathrm{~N}$ & $\mathrm{~N}$ \\
\hline Acid Yellow 129 & $\mathrm{~N}$ & $\mathrm{~N}$ & $\mathrm{~N}$ \\
\hline Acid Yellow 151 & $\mathrm{Y}$ & $\mathrm{N}$ & $\mathrm{N}$ \\
\hline Acid Yellow 17 & $\mathrm{~N}$ & $\mathrm{~N}$ & $\mathrm{~N}$ \\
\hline Acid Yellow 184 & $\mathrm{~N}$ & $\mathrm{~N}$ & $\mathrm{~N}$ \\
\hline Acid Yellow 19 & $\mathrm{~N}$ & $\mathrm{Y}$ & $\mathrm{N}$ \\
\hline Acid Yellow 219 & $\mathrm{~N}$ & $\mathrm{Y}$ & $\mathrm{N}$ \\
\hline Acid Yellow 250 & $\mathrm{~N}$ & $\mathrm{Y}$ & $\mathrm{N}$ \\
\hline Acid Yellow 38 & $\mathrm{~N}$ & $\mathrm{Y}$ & $\mathrm{Y}$ \\
\hline Acid Yellow 49 & $\mathrm{~N}$ & $\mathrm{~N}$ & $\mathrm{~N}$ \\
\hline Acid Yellow 99 & $\mathrm{Y}$ & $\mathrm{N}$ & $\mathrm{N}$ \\
\hline
\end{tabular}


APPENDIX D

\begin{tabular}{|c|c|c|c|c|c|c|c|}
\hline $\begin{array}{l}\text { Pen } \\
\text { Number }\end{array}$ & Pen Brand & $\begin{array}{l}\text { Pen } \\
\text { Type }\end{array}$ & $\begin{array}{c}\text { Ink } \\
\text { Color }\end{array}$ & $\begin{array}{c}\text { in situ } \\
\text { NR }\end{array}$ & $\begin{array}{l}\text { in situ } \\
\text { SERS }\end{array}$ & $\begin{array}{c}\text { Extraction } \\
\text { NR }\end{array}$ & $\begin{array}{c}\text { Extraction } \\
\text { SERS }\end{array}$ \\
\hline 1 & $\begin{array}{l}\text { Papermate } \\
\text { Comfortmate }\end{array}$ & Ballpoint & Black & $\mathrm{N}$ & $\mathrm{N}$ & $\mathrm{N}$ & Y \\
\hline 2 & $\begin{array}{l}\text { Papermate } \\
\text { Ball Point }\end{array}$ & Ballpoint & Black & $\mathrm{N}$ & $\mathrm{N}$ & $\mathrm{N}$ & Y \\
\hline 3 & $\begin{array}{c}\text { Papermate } \\
\text { PhD }\end{array}$ & Ballpoint & Black & $\mathrm{N}$ & $\mathrm{N}$ & $\mathrm{N}$ & Y \\
\hline 4 & $\begin{array}{l}\text { Papermate } \\
\text { PhD Multi }\end{array}$ & Ballpoint & Black & $\mathrm{N}$ & $\mathrm{N}$ & $\mathrm{N}$ & $\mathrm{Y}$ \\
\hline 5 & $\begin{array}{c}\text { Uni-ball } \\
\text { Vision Micro }\end{array}$ & $\begin{array}{c}\text { Roller } \\
\text { ball }\end{array}$ & Black & $\mathrm{N}$ & $\mathrm{N}$ & $\mathrm{N}$ & Y \\
\hline 6 & $\begin{array}{c}\text { Uni-ball } \\
\text { Vision Fine }\end{array}$ & $\begin{array}{c}\text { Roller } \\
\text { ball }\end{array}$ & Black & $\mathrm{N}$ & $\mathrm{N}$ & $\mathrm{N}$ & $\mathrm{N}$ \\
\hline 7 & $\begin{array}{c}\text { Uni Power } \\
\text { Take } 1.0\end{array}$ & Ballpoint & Black & $\mathrm{N}$ & $\mathrm{N}$ & $\mathrm{N}$ & Y \\
\hline 8 & $\begin{array}{c}\text { Pilot Precise } \\
\text { Rolling Ball } \\
\text { V5 Extra- } \\
\text { Fine }\end{array}$ & $\begin{array}{c}\text { Roller } \\
\text { ball }\end{array}$ & Black & $\mathrm{N}$ & $\mathrm{N}$ & $\mathrm{N}$ & $\mathrm{N}$ \\
\hline 9 & Pilot Dr. Grip & Ballpoint & Black & $\mathrm{N}$ & $\mathrm{N}$ & $\mathrm{N}$ & $\mathrm{Y}$ \\
\hline 10 & Pilot Dr. Grip & Ballpoint & Black & $\mathrm{N}$ & $\mathrm{N}$ & $\mathrm{N}$ & $\mathrm{Y}$ \\
\hline 11 & $\begin{array}{c}\text { AVERY } \\
\text { Triple Click }\end{array}$ & Ballpoint & Black & $\mathrm{N}$ & $\mathrm{N}$ & $\mathrm{N}$ & $\mathrm{Y}$ \\
\hline 12 & Zebra F-301 & Ballpoint & Black & $\mathrm{Y}$ & $\mathrm{Y}$ & $\mathrm{N}$ & $\mathrm{Y}$ \\
\hline 13 & Parker & Ballpoint & Black & $\mathrm{N}$ & $\mathrm{N}$ & $\mathrm{N}$ & $\mathrm{Y}$ \\
\hline 14 & $\begin{array}{c}\text { Papermate } \\
\text { Comfortmate }\end{array}$ & Ballpoint & Blue & $\mathrm{N}$ & $\mathrm{N}$ & $\mathrm{N}$ & Y \\
\hline 15 & $\begin{array}{c}\text { Uni-ball } \\
\text { Vision Micro }\end{array}$ & $\begin{array}{c}\text { Roller } \\
\text { ball }\end{array}$ & Blue & Y & Y & $\mathrm{N}$ & Y \\
\hline 16 & $\begin{array}{l}\text { Uni-ball } \\
\text { Vision Fine }\end{array}$ & $\begin{array}{c}\text { Roller } \\
\text { ball }\end{array}$ & Blue & Y & Y & $\mathrm{N}$ & $\mathrm{Y}$ \\
\hline 17 & $\begin{array}{l}\text { Uni Power } \\
\text { Tank } 1.0\end{array}$ & Ballpoint & Blue & $\mathrm{N}$ & $\mathrm{N}$ & $\mathrm{N}$ & Y \\
\hline 18 & $\begin{array}{c}\text { Zebra GR8 } \\
\text { Roller } 0.7\end{array}$ & $\begin{array}{c}\text { Roller } \\
\text { ball }\end{array}$ & Blue & Y & Y & $\mathrm{N}$ & Y \\
\hline 19 & Zebra F-301 & Ballpoint & Blue & $\mathrm{Y}$ & $\mathrm{Y}$ & $\mathrm{N}$ & $\mathrm{Y}$ \\
\hline 20 & Parker & Ballpoint & Blue & $\mathrm{N}$ & $\mathrm{N}$ & $\mathrm{N}$ & $\mathrm{Y}$ \\
\hline 21 & $\begin{array}{c}\text { Papermate } \\
\text { Comfortmate }\end{array}$ & Ballpoint & Red & $\mathrm{N}$ & $\mathrm{N}$ & $\mathrm{N}$ & Y \\
\hline
\end{tabular}




\begin{tabular}{|c|c|c|c|c|c|c|c|}
\hline 22 & $\begin{array}{c}\text { Papermate } \\
\text { Comfortmate }\end{array}$ & Ballpoint & Red & $\mathrm{N}$ & $\mathrm{N}$ & $\mathrm{N}$ & $\mathrm{Y}$ \\
\hline 23 & $\begin{array}{c}\text { Uni-ball } \\
\text { Vision Fine }\end{array}$ & $\begin{array}{c}\text { Roller } \\
\text { ball }\end{array}$ & Red & $\mathrm{N}$ & $\mathrm{N}$ & $\mathrm{N}$ & $\mathrm{N}$ \\
\hline 24 & $\begin{array}{l}\text { Pilot Precise } \\
\text { Rolling Ball } \\
\text { V5 Extra } \\
\text { Fine }\end{array}$ & $\begin{array}{c}\text { Roller } \\
\text { ball }\end{array}$ & Red & $\mathrm{N}$ & $\mathrm{N}$ & $\mathrm{N}$ & Y \\
\hline 25 & $\begin{array}{c}\text { Uni-ball } \\
\text { Vision Fine }\end{array}$ & $\begin{array}{c}\text { Roller } \\
\text { ball }\end{array}$ & Purple & $\mathrm{N}$ & $\mathrm{N}$ & $\mathrm{N}$ & $\mathrm{Y}$ \\
\hline 26 & $\begin{array}{l}\text { BIC Multi- } \\
\text { Color }\end{array}$ & Ballpoint & Black & $\mathrm{N}$ & $\mathrm{N}$ & $\mathrm{N}$ & $\mathrm{Y}$ \\
\hline 27 & $\begin{array}{l}\text { BIC Multi- } \\
\text { Color }\end{array}$ & Ballpoint & Green & $\mathrm{N}$ & $\mathrm{N}$ & $\mathrm{N}$ & $\mathrm{Y}$ \\
\hline 28 & $\begin{array}{l}\text { BIC Multi- } \\
\text { Color }\end{array}$ & Ballpoint & Blue & $\mathrm{Y}$ & $\mathrm{N}$ & $\mathrm{Y}$ & $\mathrm{Y}$ \\
\hline 29 & $\begin{array}{l}\text { BIC Multi- } \\
\text { Color }\end{array}$ & Ballpoint & Red & $\mathrm{N}$ & $\mathrm{N}$ & $\mathrm{N}$ & $\mathrm{Y}$ \\
\hline 30 & $\begin{array}{l}\text { Zebra Clip- } \\
\text { On 2-Color }\end{array}$ & Ballpoint & Black & $\mathrm{Y}$ & Y & $\mathrm{Y}$ & $\mathrm{Y}$ \\
\hline 31 & $\begin{array}{l}\text { Zebra Clip- } \\
\text { On 2-Color }\end{array}$ & Ballpoint & Red & $\mathrm{N}$ & $\mathrm{N}$ & $\mathrm{N}$ & $\mathrm{Y}$ \\
\hline \multicolumn{4}{|c|}{ Total usable spectra } & 7 & 6 & 2 & 29 \\
\hline
\end{tabular}

